\title{
WOOD ASH USED AS PARTLY SAND AND/OR CEMENT REPLACEMENT IN MORTAR
}

\author{
LISBETH M. OTTOSEN, ESBEN ØSTERGAARD HANSEN, PERNILLE E. JENSEN, \\ GUNVOR M. KIRKELUND \& PER GOLTERMAN \\ Department of Civil Engineering, Building 118, Technical University of Denmark, \\ 2800 Kgs. Lyngby, Denmark.
}

\begin{abstract}
Wood ash (WA) is the residue generated during incineration of wood and wood products. The WAs in focus of this work are from incineration of virgin wood. Physical and chemical properties of WA vary significantly depending on many factors related to the wood species and the incineration process, and the present work reports a characterization of three different WAs. Properties of mortar samples with the WAs used as partly cement and/or sand replacement are reported. Compressive strength development and porosity are the mortar properties in focus. The overall aim of the work is to evaluate the influence from the differences in ash characteristics to the properties of the mortar samples. The characteristics of the ashes did vary considerably. For example, one ash had very high loss on ignition (LoI) of $14 \%$ compared to $3 \%$ for the other ashes. Ash solubility in water ranged from $18 \%$ to $28 \%$. Two of the ashes were dry and sampled just after the incineration, whereas one ash had a water content of $15 \%$, because the ash was sprayed with water to avoid dust during ash handling at the incineration plant. Regardless of replacing cement or sand with WAs, the compressive strength decreased compared to a reference without ash, however, the decrease was small for two of the ashes. Using the ash with the high LoI resulted in significantly lower compressive strength compared to the other two ashes. The mortar samples with two of the ashes (with low LoI) had qualities, which were very encouraging in order to use WA as partly cement replacement $(<10 \%)$. At higher percentages the workability was so low that extra water needed to be added and the results depended on the water:cement ratio rather than the ash mass. Keywords: cement replacement, compressive strength, mortar, wood fly ash.
\end{abstract}

\section{INTRODUCTION}

Renewable energy plays a fundamental role in the transition towards a sustainable energy system. Traditionally, bioenergy has been considered carbon neutral as the released carbon is absorbed by the harvested crops' regrowth. Wood ash (WA) is the residue from combustion of wood and wood products (chips, saw dust, bark, etc.). According to the European Waste Catalogue and hazardous residues list [1], both bottom ash and fly ash from combustion of untreated wood are classified as non-hazardous wastes. This paper is focused on the use of WA in concrete. Use as cement replacement offers environmental gains from lowering $\mathrm{CO}_{2}$ emissions, as $\mathrm{CO}$ emission from cement production currently represents about $5 \%$ of the anthropogenic global emissions. Also conservation of natural resources and possible financial benefits makes the use of WA in concrete interesting.

Physical and chemical properties of WA vary significantly depending on many factors: species of wood, method of combustion including temperature, other fuels co-combusted with the wood and method of WA collection [2]. While the elemental composition of the WA is determined by the inorganic constituents in the parent bio-mass, the crystallinity and 
mineralogy depend on the combustion technique used [3]. The evaluation of WA for use in concrete begins with mortar testing. Mortar is similar to concrete in that it contains cement, water and aggregate, except that in mortar graded sand is the only aggregate present. The present investigation includes experimental work with three different WAs in order to compare the characteristics and relate them to properties of mortar containing the WAs.

Focus of the present work is: (1) to compare characteristics of different WAs and the effect on the compressive strength of mortar with the WAs used as partly cement or sand replacement and (2) discuss the effect of prewashing WA in water and the use of the washed WA as combined sand and cement replacement.

\subsection{Wood ashes}

\section{MATERIALS AND METHODS}

WAs in the investigation were sampled from Danish plants in September 2014:

WA1: from Køge Kraftvarmeværk. Incinerate waste wood from production of parquet floor by Junckers Industries A/S. Wood species were ash, merbau, maple, oak, jatoba and beech. The ash was sampled after incineration and subsequent watering to about $15 \%$ water to limit dust during ash handling.

WA2: fly ash from HOFOR Amagerværket blok 3, which fired only wood pellets at the time of sampling.

WA3: a fly ash from VERDO Randers and was from incineration of $~ 90 \%$ wood and $\sim 10 \%$ bio-residues as nutshells and seed grain screenings. Just after incineration water is added to the ash to avoid dust.

\subsection{Characterization}

Characterization and extraction experiments were made with dried WA $\left(105^{\circ} \mathrm{C}, 24\right.$ hours $)$. Concentrations of $\mathrm{Ca}, \mathrm{K}, \mathrm{Na}, \mathrm{P}, \mathrm{Cd}, \mathrm{Cu}, \mathrm{Pb}$ and $\mathrm{Zn}$ were measured after pre-treatment of the WA in accordance to Danish Standard DS259 'Determination of metals in water, sludge and sediments - General guidelines for determination by atomic absorption spectrophotometry in flame': $1.0 \mathrm{~g}$ WA and $20.0 \mathrm{~mL}(1: 1) \mathrm{HNO}$ was heated at $200 \mathrm{kPa}\left(120^{\circ} \mathrm{C}\right)$ for 30 minutes. Filtration through $0.45 \mu \mathrm{m}$ filter and the concentrations were measured with ICP-OES instead of AAS as prescribed in the standard. Ash pH was measured by suspending $10.0 \mathrm{~g}$ ash in $25 \mathrm{~mL}$ distilled water. After 1 hour agitation $\mathrm{pH}$ was measured directly in the suspension with a pH electrode. The suspension was filtered followed by measurement of $\mathrm{Cl}$ and $\mathrm{SO}$ concentrations by Ion Chromatography and $\mathrm{Ca}, \mathrm{K}$ and $\mathrm{Na}$ by ICP-OES. Loss on ignition (LoI) was found after 30 minutes at $550^{\circ} \mathrm{C}$. Water content was measured as weight loss after 24 hours at $105^{\circ} \mathrm{C}$ (calculated as weight loss over the weight of the wet sample). Triple-determinations were made for each of these analyses. Morphology was evaluated by SEM (no pre-treatment of the samples was made). Solubility in water was evaluated: $50.0 \mathrm{~g}$ ash suspended in $500 \mathrm{~mL}$ distilled water and agitated for $1 \mathrm{~min}$. After settling the water was decanted. New $500 \mathrm{~mL}$ distilled water added. This was repeated so the ash was washed three times. Finally the suspension was filtered and the ash dried and weighed.

\subsection{Water-washing procedure for WA}

Water washing of WA was performed to wash out the soluble salts. The washing procedure used followed the same procedure as the determination of water solubility (chapter 2.2) 
except from the amount of ash and water being higher (100 g WA and $1000 \mathrm{~mL}$ water). Mortar prisms were casted with water-washed WA1 and WA2 and the washed WA's are denoted WA1-W and WA2-W.

\subsection{Overview over casted mortar prisms}

The casted mortar prisms are summarized in Table 1. The last row in the table mentions a matrix, where sand and/or cement was replaced with WA1-W.

The exact percentages of replacement are shown later in Fig. 1. Altogether, 26 different mortars were cast to form the matrix and in these samples the water to powder (cement and ash) content was kept constant at 0.5 .

\subsection{Mortar prisms preparation and compressive strength measurement}

The procedure and recipe base for the mortar prisms was from DS/EN 196-1 [4]: $225 \mathrm{~mL}$ water, $450 \mathrm{~g}$ cement (ordinary Portland) and $1350 \mathrm{~g}$ sand. Reference prisms were made following the recipe and procedure from DS/EN 196-1. In the mortar prisms with WA either a chosen mass percentage of cement, sand or both were replaced with WA.

Table 1: Overview of the mortars cast in this investigation.

\begin{tabular}{llllc}
\hline & Days & WA1 & WA2 & WA3 \\
\hline Cement replacement $-5 \%$ and 10\% & $7-14-28$ & $\mathrm{X}$ & $\mathrm{X}$ & $\mathrm{X}$ \\
Sand replacement $-10 \%$ & $7-14-28$ & $\mathrm{X}$ & $\mathrm{X}$ & $\mathrm{X}$ \\
$\begin{array}{l}\text { Cement replacement washed WA }- \\
5 \% \text { and 10\% }\end{array}$ & 7 & $\mathrm{X}$ & $\mathrm{X}$ & \\
$\begin{array}{l}\text { Matrix with sand and/or cement } \\
\text { replacement with washed WA1-W }\end{array}$ & 7 & $\mathrm{X}$ & & \\
\hline
\end{tabular}
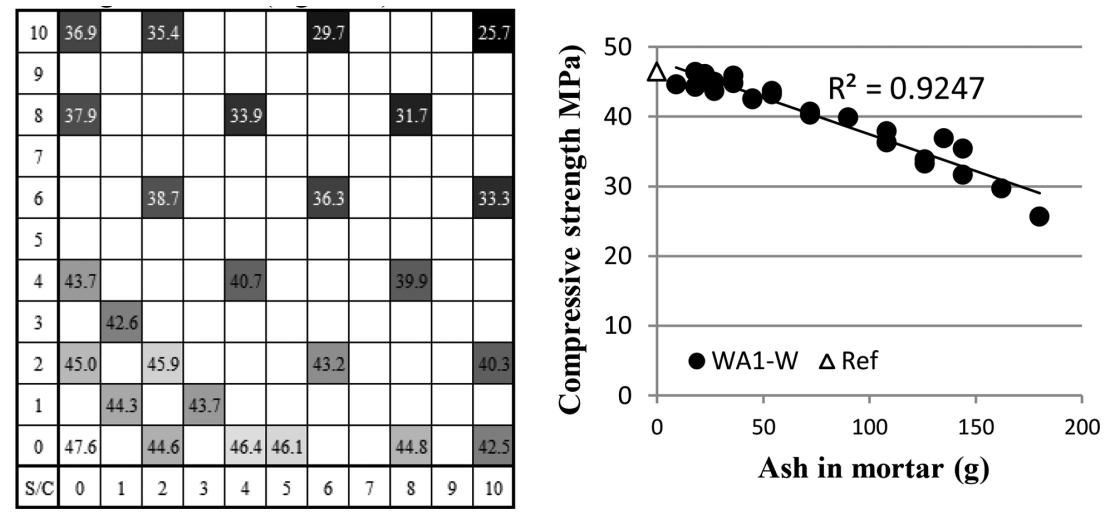

Figure 1: (A) Compressive strength (7 days) for mortar with varying percentages of sand (s) and/or cement (c) replacement with WA1-W. Darkest color lowest strength. (B) Compressive strength vs. ash mass. 
The WA was used with the water content as received. To all mortar samples with WA as cement replacement the amount of water $(225 \mathrm{~mL})$ was as prescribed in the mortar recipe (WA1 had a high water content and this water was subtracted the water added into the mixing bowl). To the mortar with WA2 and WA3 as sand replacement additional water was added directly into the mixing bowl to obtain a workability of the wet mortar similar to that of the reference mortar without WA. Without addition of extra water the mortar was too dry to be casted. The amount of extra water to the mortars with $10 \%$ sand replacement: $62 \mathrm{~g}$ WA1, $25 \mathrm{~g}$ WA2 and $67 \mathrm{~g}$ WA3. The water to powder ratio (W/P ratio) was kept constant at 0.5 in the mortar constituting the matrix meaning that the water to cement ratio (W/C ratio) varied. Except from extra water to some mortar mixtures the mixing and moulding were carried out as prescribed in DS/EN 196-1. The mould consisted of three horizontal compartments so that three prismatic specimens, $40 \mathrm{~mm} \times 40 \mathrm{~mm}$ in cross section and $160 \mathrm{~mm}$ in length, were prepared simultaneous for each mixture. Demoulding was carried out after 24 hours and the samples were cured horizontally in a water bath. The ambient temperature during curing was about $23^{\circ} \mathrm{C}-25^{\circ} \mathrm{C}$, which was higher than the $20^{\circ} \mathrm{C} \pm 1^{\circ} \mathrm{C}$ as prescribed in DS/EN 196- 1 .

The mortar prisms were segmented into two in a three-point loading setup, where after the compressive strength was measured for each segment, i.e. six measurements for each mortar recipe. The testing machine for measurement of compressive strength was a Mohr \& Federhaff AG-49.

\subsection{Porosity of mortar}

The mortar segments for porosity measurements were dried at $50^{\circ} \mathrm{C}$ until stable weight (approx. three weeks). The samples were placed in a desiccator. Air was evacuated from the desiccator for 3 hours. Distilled water was led in to cover the samples. The vacuum was kept for 1 hour. Following the pressure was levelled out to atmospheric pressure during at least 12 hours. The water saturated samples were weighed over and under water.

The porosity was measured for 18 of the mortar prisms in the matrix (double determination). After segmenting the prisms into two during the three-point bending test, two segments were used for porosity measurements and the remaining four for compressive strength.

\section{RESULTS AND DISCUSSION}

\subsection{Characterization of the ashes}

The results from the characterization of the three WAs are seen in Table 2.

The total soluble fraction of the WAs is between $17.8 \%$ and $28 \%$. The $\mathrm{pH}$ of the WAs is high showing that hydroxides are leached $(\mathrm{pH}$ is measured in a suspension of WA in distilled water) and comparing the water soluble fraction of $\mathrm{K}$ and $\mathrm{Na}$ to the total concentrations of the same elements shows, that by far the major fractions of these elements are water soluble. WA generally contains high levels of soluble salts [5]. The leaching reactions in water are rapid and substantial quantities of $\mathrm{K}, \mathrm{Na}$ and hydroxides are leached from the ash [6].

Coal fly ash to be used in concrete must conform to the requirements in EN 450-1 (2012) [7]. As there is no standard for requirements for use of alternative ashes such as WA, the characteristics in Table 2 are compared to EN 450-1 bearing in mind that this standard is valid for coal fly ash only. 
Table 2: Characteristics of the experimental ashes.

\begin{tabular}{lccc}
\hline & WA1 & WA2 & WA3 \\
\hline General parameters & & & \\
$\mathrm{pH}$ & 12.9 & 13.1 & 12.5 \\
Loss on ignition $(\%)$ & 2.9 & 2.9 & 13.9 \\
Water content $(\%)$ & 15.2 & 0.7 & 1.8 \\
Water soluble fraction & & & \\
Total solubility $(\%)$ & 24.2 & 28.0 & 17.8 \\
Water soluble Cl $(\mathrm{g} / \mathrm{kg})$ & 32 & 60 & 3.6 \\
Water soluble $\mathrm{SO}(\mathrm{g} / \mathrm{kg})$ & 55 & 55 & 58 \\
Water soluble Ca $(\mathrm{g} / \mathrm{kg})$ & 2.1 & 2.9 & 0.05 \\
Water soluble $\mathrm{K}(\mathrm{g} / \mathrm{kg})$ & 61 & 108 & 47 \\
Water soluble $\mathrm{Na}(\mathrm{g} / \mathrm{kg})$ & 1.2 & 1.6 & 0.3 \\
Total concentrations $(\mathrm{DS} 259)$ & & & \\
$\mathrm{Ca}(\mathrm{g} / \mathrm{kg})$ & 56 & 86 & 155 \\
$\mathrm{~K}(\mathrm{~g} / \mathrm{kg})$ & 62 & 108 & 61 \\
$\mathrm{Na}(\mathrm{g} / \mathrm{kg})$ & 1.1 & 1.6 & 13.6 \\
$\mathrm{P}(\mathrm{g} / \mathrm{kg})$ & 6.5 & 5.5 & 4.6 \\
$\mathrm{Zn}(\mathrm{mg} / \mathrm{kg})$ & 400 & 1680 & 410 \\
$\mathrm{Cu}(\mathrm{mg} / \mathrm{kg})$ & 76 & 360 & 82 \\
$\mathrm{~Pb}(\mathrm{mg} / \mathrm{kg})$ & 52 & 4.0 & 50 \\
$\mathrm{Cd}(\mathrm{mg} / \mathrm{kg})$ & 4.8 & & 4.1 \\
\hline
\end{tabular}

1. The chloride content is very important in relation to reinforced concrete, as high chloride content increase risk for reinforcement corrosion. The allowed chloride content for coal fly ash is $1.0 \mathrm{~g} / \mathrm{kg}$ in accordance to DS/EN 450-1. Neither of the WAs meets this limit.

2. The sulphate content expressed as $\mathrm{SO}_{3}$ must not exceed $30 \mathrm{~g} / \mathrm{kg}$ by mass (EN 450-1), corresponding to $12.01 \mathrm{~g} \mathrm{~S} / \mathrm{kg}$. The analytical method linked to this limiting value (in EN 196-2) vary from the one of the present work, where water soluble $\mathrm{SO}_{4}{ }^{2-}$ is measured. Calculating the concentration of $\mathrm{S}$ from the water soluble $\mathrm{SO}_{4}^{2-}$ the concentrations are: WA1 $18.4 \mathrm{~g} \mathrm{~S} / \mathrm{kg}$; WA2 $18.4 \mathrm{~g} \mathrm{~S} / \mathrm{kg}$ and WA3 $19.4 \mathrm{~g} \mathrm{~S} / \mathrm{kg}$ and thus even the soluble S concentration is higher than in the limiting value from EN 450-1, indicating that the sulphate content is probably too high even though the analytical methods differ. High sulphate content in the ash is an internal sulphate source, which can cause sulphate attack of the concrete.

3. The content of total phosphorous $\left(\mathrm{P}_{2} \mathrm{O}_{5}\right)$ shall not be greater than $5.0 \%$ by mass (in accordance to EN 450-1). The analytical method used to measure the PO content must follow ISO 29581-2 based on XRF. As good consistency between P concentrations measured by the method in the present investigation and XRF analysis was seen for SSAs (Ottosen et al. 2013), the actual concentrations measured are evaluated towards the $5.0 \%$ by mass (50 $\mathrm{g} \mathrm{P}_{2} \mathrm{O}_{5} / \mathrm{kg}$ ), which corresponds to a concentration of $21.8 \mathrm{~g} \mathrm{P} / \mathrm{kg}$. Compared to this, the $\mathrm{P}$ concentration of the investigated WAs meets the limiting value. 
4. In EN 450-1 (2012) the ash is categorized on basis of the $\mathrm{LoI}$ (measured at $950^{\circ} \mathrm{C}$ as prescribed in EN 196-2): A 5\%, B 7\% and C 9\%. The LoI in Table 2 were found at $550^{\circ} \mathrm{C}$, and are thus less than if ignited at $950^{\circ} \mathrm{C}$ so the LoI in Table 2 cannot be used directly for categorizing the WAs. However, WA3 has already at the low temperature a too high LoI to be used as it exceeds category $\mathrm{C}$.

In summary, the investigated WAs do not meet the requirements set in EN 450-1 for coal fly ash to be used in concrete. The properties of concrete with WA thus need to be determined and such concrete must be viewed as a new material where the possible use needs to be outlined.

WA1 was watered at the combustion facility to improve handling and contained larger lumps of agglomerated ash particles (Fig. 2). For comparison WA2 without lumps is shown. The lumps were formed during self-hardening. Self-hardening is formation of new phases [5]. Hydration of $\mathrm{CaO}$ forming $\mathrm{Ca}(\mathrm{OH})_{2}$ is rapid and exothermic. Carbonation of $\mathrm{Ca}(\mathrm{OH})$ occurs in presence of water and carbon dioxide. The calcite $\left(\mathrm{CaCO}_{3}\right)$ thus formed precipitates in a layer on the ash surfaces and in the pores. Ettringite formation contributes to the early solidification; however, if the $\mathrm{pH}$ is too low or soluble $\mathrm{Al}$ is lacking, $\mathrm{CaSO}_{4}$ is formed instead. Hydration of amorphous silicate phases may also contribute [6] and C-S-H gel was identified by SEM-EDX [8]. The importance of each reaction and the relation between WA properties and its self-hardening behavior is though yet not known [9], though a deeper knowledge is necessary in order to understand and evaluate the quality of WA for use in concrete.

\subsection{The development in compressive strength 7-28 days}

The strength development from 7 to 28 days for the mortar with the investigated WAs as cement (5\% and $10 \%)$ or sand $(10 \%)$ replacement is shown in Fig. 3.

Figure 3 shows decreasing compressive strength with increasing amount of ash $(5 c>10 c>10 s)$. Decreasing strength with increasing cement replacement with WA is in consistency with literature; see e.g. [10]. Extra water was added to the prisms where WA was used as sand replacement, and thus the decrease in compressive strength is a combination of

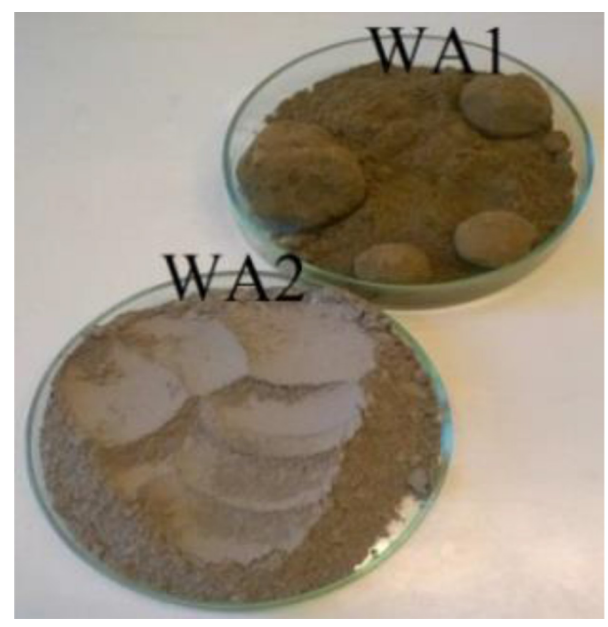

Figure 2: A1 and WA2 as received. 


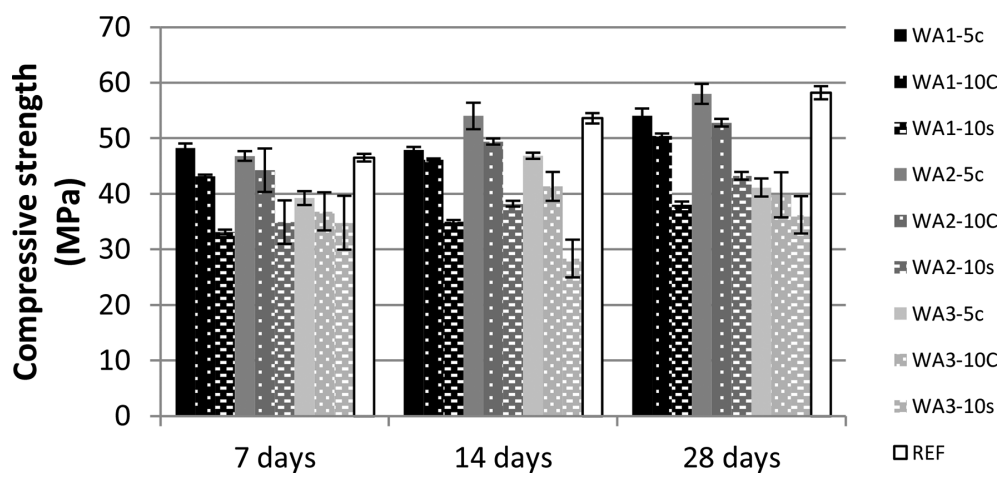

Figure 3: Strength development for mortar prisms with cement (c) or sand (s) replaced with WA. The error bars show standard deviation.

ash and higher W/P ratio. There is a clear tendency for the compressive strength of mortar prisms with WA3 to be lower than for the corresponding prisms with the two other ashes. It may be related to the high LoI of WA3 (about 14\% compared to 3\%, Table 2) as the organic part (expressed as LoI) will not contribute to the compressive strength, but on the contrary the organic matter may add to spaces without strength.

The prisms with 5\% cement replacement with WA2 have similar compressive strength as the reference mortars without ash. The strength of the prisms with 5\% cement replacement with WA1 was slightly less. At 10\% cement replacement the strength decreased to $86 \%-93 \%$ (WA1) and 90\%-95\% (WA2) compared to the reference prism. Whether the WA particles act as filler material within the cement paste matrix or as binder cannot be decided from the experiments performed here. Ramos et al. [8] reported compressive strength similar to a reference for prisms with $10 \%$ and $20 \%$ cement replacement with WA from wood fired at high temperature. Works performed with WA from small burning facilities [11-13] all found that WA as a partial cement replacement material in mortar at all levels of cement replacement (between 5\% and 30\%) reduced the compressive strength. Thus literature reports results where cement replacement with WAs did not result in strength loss and in other cases strength loss was seen even at 5\% replacement. Thus differences in WA characteristics influence concrete properties significantly. It seems from literature as if cement replacement with WA from incineration of wood at high temperatures gives the best result. The WAs of the present investigation were originating from high temperature incineration. WA1 and WA2 confirm the hypothesis of ashes fired at high temperature can be used as partly cement replacement without significant compressive strength loss, but WA3 contradicts this. However, the combustion leading to WA3 was inefficient, which can be seen from the high LoI, so the hypothesis is only valid in case of efficient combustion at the high temperature.

\subsection{Strength development washed ashes}

The seven days compressive strength for mortar prisms with 5\% and $10 \%$ cement replacement with WA1 and WA2 as received and water washed is shown in Fig. 4. The soluble fractions were: WA1 24\% and WA2 28\%. These fractions were washed out of the WAs before casting the mortar in the WA-W prisms. The differences in compressive strength were within $5 \mathrm{MPa}$ between the mortar with washed and raw WA for the same replacement percentage. 


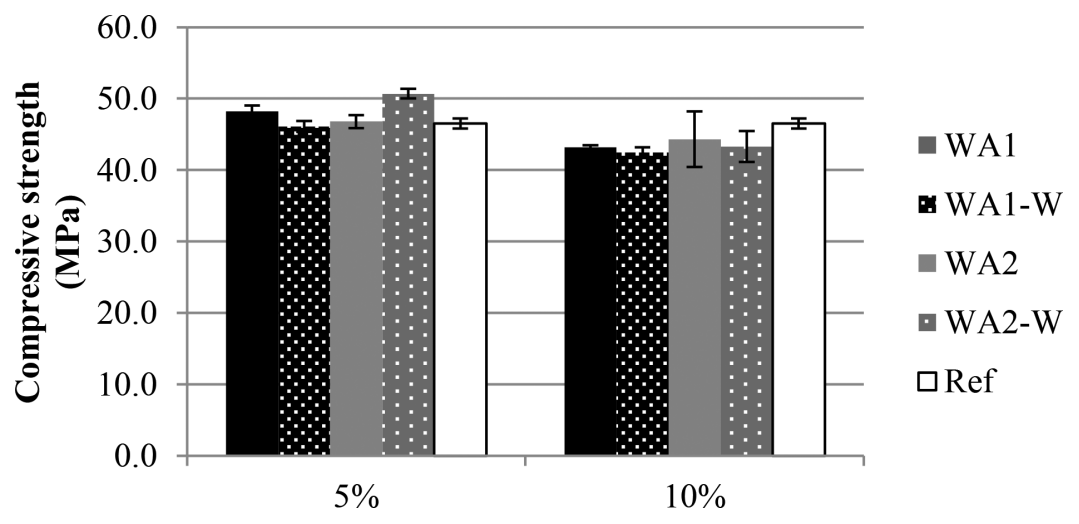

Figure 4: Compressive strength (seven days) for mortar prisms with $5 \%$ and $10 \%$ cement replacement with raw or washed WA1 and WA2.

Thus the effect from washing the ash on the mortar compressive strength was limited. It must though be stressed, that the test was made only for prisms cured for 7 days. The strength development over time should be measured, as a possible pozzolan effect often shows after longer casting times (e.g. coal fly ash).

3.4 Compressive strength and porosity for mortar with partly cement and/or sand replacement with washed WA1

The compressive strength for the mortars in the matrix with varying sand and/or cement replaced with WA1-W is shown in Fig. 1. In Fig. 4A the lightest colors mark the highest compressive strength, and the dark the lowest. The $10 \%$ sand replacement corresponds to $135 \mathrm{~g}$ WA and $10 \%$ cement replacement $45 \mathrm{~g}$ WA. Figure 1B shows the same results, but with no distinction whether WA1-W replaces sand or cement. It is seen that the compressive strength is linear dependent on the mass of ash in the mortar, regardless of replacing sand or cement. The W/P ratio was kept constant at 0.5 in all mortar mixtures, but as seen from Fig. 1 the compressive strength of the mortars varied from 25.7 to $45.3 \mathrm{MPa}$, and thus the compressive strength is not dependent on the W/P ratio. On the contrary, the relation between water:cement $(\mathrm{W} / \mathrm{C})$ ratio and compressive strength is linear $\left(\mathrm{R}^{2}=0.95\right)$ (Fig. 5) and as expected the strength is decreasing with increasing w/c ratio. This implies that WA1-W has no pozzolanic properties, at least not during the first 7 days which was the curing time for the actual test. Low initial pozzolanic property of WA1-W could also be expected, since the selfhardening process happened during the watering of the ash at the incineration facility and following the soluble fraction was washed out in the lab during the washing procedure. In summary, the washed WA WA1-W cannot replace cement as a binder.

The apparent dependency of the compressive strength on ash mass (Fig. 1) is rather a dependency on the $\mathrm{W} / \mathrm{C}$ ratio, which links directly to the ash amount. The direct relation between W/C ratio and compressive strength is through the porosity of the mortar. The compressive strength of a material is directly dependent on the porosity, which is also the case for the mortar prisms with the investigated WAs (Fig. 6)

Whether WA1 can be used as binder without initial washing still needs clarification. Figure 4 showed that washing WA1 resulted in a slightly decreased compressive strength for the cast 


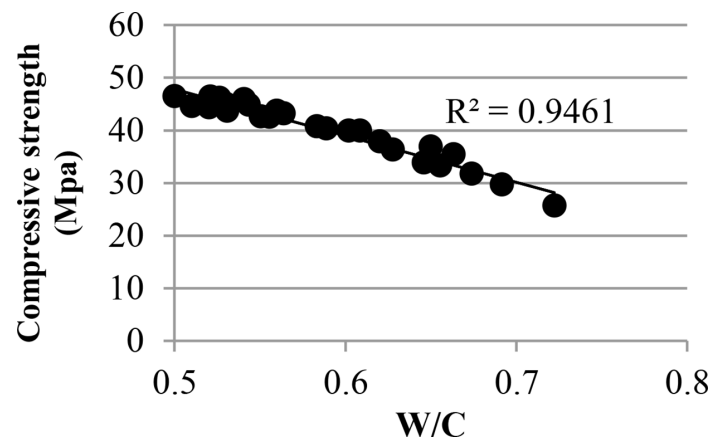

Figure 5: Compressive strength vs. W/C ratio for mortar samples (7 days) with WA1-W. W/ relation was kept constant at 0.5 .

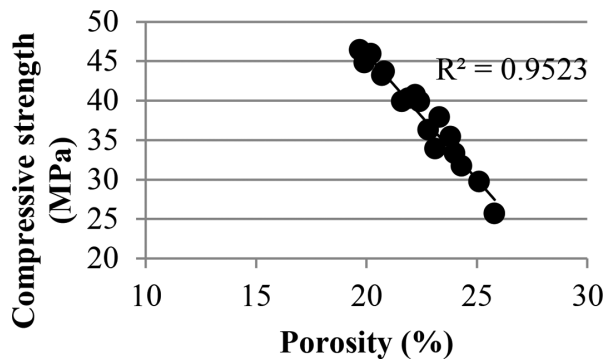

Figure 6: Compressive strength vs. porosity for the mortar prisms with varying amount of sand and/or cement replaced with WA.

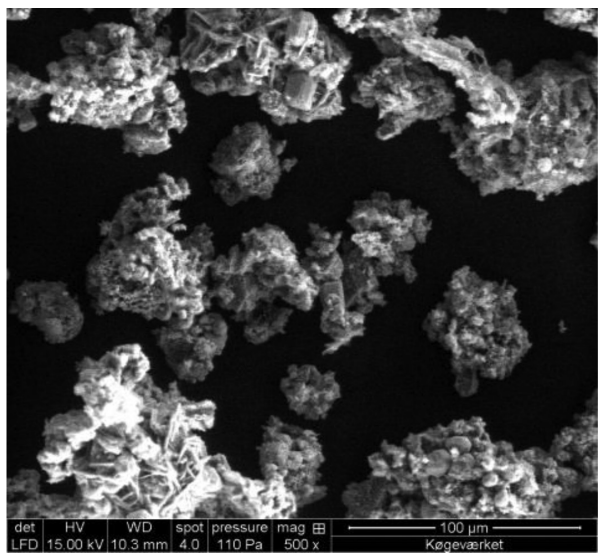

Figure 7: SEM image of WA1 (as received).

mortar prisms with both 5\% and 10\% cement replacement compared to the same prisms with WA1 as received (same W/P ratio). The compressive strength of the mortar with 5\% cement replacement with WA1 was slightly higher than the strength of the reference even though the W/C ration of the reference was higher ( 0.50 compared to 0.53$)$, and this might indicate a pozzolanic property. 
Extra water is needed to keep workability at a WA mass higher than about $45 \mathrm{~g}$ (experience from WA2 and WA3). In the matrix with different mortar mixtures were tested, it was decided on beforehand to keep the W/P ratio constant at 0.5 . Thus, in order to evaluate the effect on the compressive strength from the use of WA alone, it is necessary to choose a mortar mixture with a higher W/C ratio than 0.5 . The higher W/P ratio needed when casting mortar with WA can be due to both the porosity of the WA particles and the irregular and not rounded morphology of the ash particles (see Fig. 7).

\section{CONCLUSIONS}

In lack of requirements for WA to be used in concrete, the three investigated WAs were compared to the requirements set for coal fly ash, which they did not meet for $\mathrm{Cl}$ and $\mathrm{S}$. The properties of concrete with WA thus need to be evaluated for other possible other uses than concrete with coal fly ash. One of the ashes had been watered during ash handling at the combustion facility and self-hardening had occurred, seen as larger lumps in the otherwise fine-powdered ash.

One of the ashes had a too high LoI and using this ash resulted in the lowest compressive strength both when used as partly sand and cement replacement. For the two other ashes a 5\% cement replacement did not result in compressive strength loss. Washing the ash in water to eliminate the soluble fraction did lower the compressive strength of the mortar slightly compared to unwashed ash.

A matrix with 28 different mortar recipes (variation in percentages of sand and/or cement replacement) was made. For all recipes the W/P ratio was kept constant. The result showed that the compressive strength was strongly dependent on the W/C ratio There seemed to be a dependence on the compressive strength by the amount of ash in the mortar, but this dependence was rather caused by the W/C ratio, as the W/P ratio was kept constant. The mortar porosity increased linearly with decreasing W/C ratio. Using WA as partly cement replacement at low percentages $(<10 \%)$ seems promising. At higher percentages extra water is needed to keep an acceptable workability, however here the higher W/C ratio causes lower compressive strength.

\section{ACKNOWLEDGEMENTS}

The students Saboor Aghazadeh, Kristian Nyvang Jensen and Kasper Larsen are acknowledged for carefully conducting the experiments with WA2 and WA3.

\section{REFERENCES}

[1] Commission of the European Communities. Establishing a list of wastes pursuant to Article 1(a) of Council Directive 75/442/EEC on waste and Council Decision 94/904/ EC establishing a list of hazardous waste pursuant to Article 1(4) of Council Directive 91/689/EEC on hazardous waste. Official Journal of the European Communities L 226/3, 2000.

[2] Etiégni, L. \& Campbel, A.G., Physical and Chemical Characterization of wood ash. Bioresource Technology, 37, pp. 173-178, 1991. http://dx.doi.org/10.1016/0960-8524(91)90207-Z

[3] Umamaheswaran, K. \& Batra, V.S., Physico-chemical characterisation of Indian biomass ashes. Fuel, 87, pp. 628-638, 2008. http://dx.doi.org/10.1016/j.fuel.2007.05.045

[4] DS/EN 196-1 Methods of testing cement. Determination of strength 
[5] Steenari, B.-M. \& Lindqvist, O., Stabilisation of biofuel ashes for recycling to forest soil. Biomass and Bioenergy, 13, pp. 39-50, 1997. http://dx.doi.org/10.1016/S0961-9534(97)00024-X

[6] Etiégni, L. \& Campbel, A.G., Physical and chemical characterization of wood ash. Bioresource Technology, 37, pp. 173-178, 1991. http://dx.doi.org/10.1016/0960-8524(91)90207-Z

[7] EN 450-1 (2012) Fly ash for concrete. Definition, specifications and conformity criteria

[8] Ramos, T., Matos, A.M. \& Sousa-Coutinho, J., Mortar with wood waste ash: Mechanical strength carbonation resistance and ASR expansion. Construction and Building Materials, 49, pp. 343-351, 2013. http://dx.doi.org/10.1016/j.conbuildmat.2013.08.026

[9] Illikainen, M., Tanskanen, P., Kinnunen, P., Körkkö, M., Peltosaari, O., Wigren, V., Österbacka, J., Talling, B. \& Niinimäki, J., Reactivity and self-hardening of fly ash from the fluidized bed combustion of wood and peat. Fuel, 135, pp. 69-75, 2014. http://dx.doi.org/10.1016/j.fuel.2014.06.029

[10] Berra, M., Mangialardi, T. \& Paolini, A.E., Reuse of woody biomass fly ash in cementbased materials. Construction and Building Materials, 76, pp. 286-296, 2015. http://dx.doi.org/10.1016/j.conbuildmat.2014.11.052

[11] Udoeyo, F.F. \& Dashibil, P.U., Sawdust ash as concrete material. Journal of Materials in Civil Engineering, 14(2), pp. 173-176, 2002. http://dx.doi.org/10.1061/(ASCE)0899-1561(2002)14:2(173)

[12] Elinwa, A.U. \& Ejeh, Y.A., Ash from timber waste as cement replacement material. Cement \& Concrete Composites, 24, pp. 219-222, 2004. http://dx.doi.org/10.1016/S0958-9465(01)00039-7

[13] Abdullahi, M., Characteristics of wood ASH/OPC concrete. Leonardo Electronic Journal of Practices and Technologies, 5(8), pp. 9-16, 2006. 